Review

Immunology and Cell Biology

\title{
Hematopoiesis leading to a diversity of dendritic antigen presenting cell types
}

Sawang Petvises ${ }^{1}$ and Helen C O'Neill ${ }^{1}$

${ }^{1}$ Stem Cell and Immunology Lab

Research School of Biology

The Australian National University

Canberra ACT AUSTRALIA

Correspondence: Professor HC O’Neill, Division of Biomedical Sciences, Research School of Biology, The Australian National University, Canberra ACT 0200, Australia. Email: Helen.ONeill@anu.edu.au 


\begin{abstract}
Hematopoietic stem cells (HSC) undergo expansion and differentiation giving rise to all terminally differentiated blood cells throughout life. HSC are found in distinct anatomical sites during development, and in adults, hematopoiesis occurs predominantly on the luminal side of the bone cavity in bone marrow. Millions of newly formed blood cells are generated per second to accommodate the short half-life of hematopoietic cells. In order for this to happen, HSC must sustain their self-renewal capacity as well as their capability to commit and differentiate towards multiple cell lineages. Development of the hematopoietic system is finely regulated as the animal ages, so that it does not become exhausted or misdirected. This review covers aspects of hematopoietic development from the embryonic period through adult life in relation to development of dendritic cells (DC). It also considers a role for HSC in extramedullary sites and their possible role in myelopoiesis with formation of tissue-specific antigen presenting cells (APC).
\end{abstract}

Keywords: hematopoiesis, hematopoietic stem cells, dendritic cells, myelopoiesis 


\section{EARLY HEMATOPOIESIS}

The hematopoietic and cardiovascular organ systems are the first to emerge during embryogenesis because the embryo requires a functional heart, vascular system, and blood for survival and growth in the early post-implantation period. Blood cell development in the embryo depends on gastrulation and mesoderm formation. Mesodermal cells contribute to the heart, the aorta in the embryo proper, formation of hematopoietic cells in yolk sac and vascular interconnection in the embryo. ${ }^{1}$ Embryonic hematopoiesis in mice begins after gastrulation at embryonic day 6 (E6), when mesodermal cells commit to becoming hematopoietic cells. ${ }^{2}$ The sequential sites for hematopoiesis during embryonic development then include yolk sac, the aorta-gonad-mesonephros (AGM) region, placenta, fetal liver, spleen, and finally bone marrow. ${ }^{3}$

Yolk sac, a bilayer structure of mesoderm and endoderm-derived cell layers, is the initial site for blood cell formation. The first hematopoietic precursors derive from mesoderm that gives rise to the hemangioblast, a bipotential precursor for blood and endothelium that enters the yolk sac to initiate primitive hematopoiesis across E7-E7.5. Blood cells produced at this time are primitive hematopoietic cells consisting mainly of large nucleated red blood cells. ${ }^{4}$ The presence of definitive hematopoietic progenitors then marks the start of a second wave of blood cell production on day E8.5. ${ }^{5}$ However, the microenvironment in the yolk sac does not support the differentiation of definitive hematopoietic progenitors. These therefore exit the yolk sac via the vitelline veins. Following transient appearance in the AGM region, HSC are seen to colonize fetal liver passing through umbilical cord vessels of the placenta where they contribute to robust expansion and definitive hematopoiesis.

HSC then appear in the fetal liver at E11.5 where they undergo proliferation and differentiation, with maximum expansion of HSC across E15.5-E16.5, followed by a decline in cell numbers. ${ }^{6} \mathrm{CFU}-\mathrm{E}$ and proerythroblasts prevail in early fetal liver, whereas myeloid 
and lymphoid progenitors accumulate at later stages. Modification of the liver microenvironment during fetal development occurs in preparation for HSC expansion and lineage differentiation ${ }^{7}$, consistent with phenotypic changes in HSC across different developmental stages. ${ }^{8}$

Bone development begins at E12.5 as mesenchymal condensations are observed. Briefly, mesenchymal progenitor cells first give rise to chondrocytes that create a cartilaginous framework for bone. Chondrocytes are later replaced by osteoblastic cells that build up calcified bone through endochondral ossification to form the bone marrow cavity. ${ }^{9}$ Vascular invasion into the bone then facilitates the circulation and seeding of HSC. Clonogenic hematopoietic activity in bone marrow can be found at $\sim$ E17.5 and persists throughout postnatal life. ${ }^{10}$

Hematopoiesis in fetal spleen occurs from E13 until the first weeks of the postnatal period. Hematopoietic progenitors from fetal liver migrate to fetal spleen at E13-E14 and undergo proliferation and differentiation to give mature blood cells. In contrast to fetal liver, fetal spleen does not have significant hematopoietic activity. ${ }^{11}$ Hematopoiesis in fetal liver depends on expansion of progenitors, while hematopoiesis in fetal spleen relies on immediate hematopoietic precursors derived from fetal liver which home directly to spleen. Special microenvironments or niches in fetal spleen appear to restrict or favor the development of particular blood cell lineages. $^{12}$

\section{PROPERTIES OF HEMATOPOIETIC STEM CELLS}

In adult humans, bone marrow is the major hematopoietic organ producing more than $10^{9}$ mature blood cells per day. Due to the short half-life of mature cells, continuous production of cells depends on the ability of HSC to self-renew and differentiate to give all blood cell types. ${ }^{13}$ In the steady-state, specialized niches in bone marrow provide an optimal 
microenvironment for maintenance of HSC by regulation of their self-renewal and differentiative capacity, and conservation of their multipotency throughout cell division. ${ }^{14}$

Self-renewal is driven intrinsically by gene expression and modulated through HSC interaction with extrinsic cues in the environment. HSC niches are crucial regulators which determine whether symmetric or asymmetric cell division occurs. ${ }^{15}$ During asymmetric division, HSC form a daughter cell and another HSC. Asymmetric division has been described for several tissue-specific stem cells, and several cell fate regulators including Notch, HoxB4, and Sonic hedgehog have been shown to play a role in the self-renewal process. ${ }^{16-19}$ Wnt signaling is important for self-renewal because induced expression of a frizzled ligand-binding domain, an inhibitor of the Wnt signaling pathway, leads to inhibition of HSC growth in vitro. ${ }^{20}$

Lineage commitment is the process by which HSC become restricted in their differentiation and develop into a fully committed progenitor of a single blood cell lineage. ${ }^{21}$ All murine adult hematopoietic cells derive from the multipotential HSC. This single cell type can restore the mature peripheral population of hematopoietic or blood cells in lethally irradiated recipient mice via bone marrow transplantation. Murine HSC were first characterized by their lack of lineage (Lin) specific antigens, their expression of Sca-1 (stem cell associated antigen) and c-Kit, and low expression of Thy- $1 .^{22}$ This subset was later classified as the Lin $^{-} \mathrm{Sca}-1^{+} \mathrm{c}-\mathrm{Kit}^{+}$compartment (LSK). Within the HSC hierarchy, LSK represent a diverse group which can be classified as long-term self-renewing HSC (LT-HSC), shortterm, or transiently, self-renewing HSC (ST-HSC), and multipotential progenitors (MPP). ${ }^{23,24}$

LT-HSC have capacity for life long reconstitution of the hematopoietic system. In mice, they are highly enriched in the LSK-Thy $1.1^{\text {lo }}$ cell fraction that can be further purified as Flk$2^{-}$cells. $^{25}$ The CD150, CD244 and CD48 signaling lymphocyte activation molecules have 
recently been found to discriminate HSC subpopulations such that, LSKCD $150^{+} \mathrm{CD}^{-} 8^{-}$

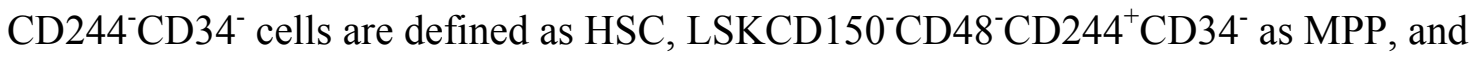

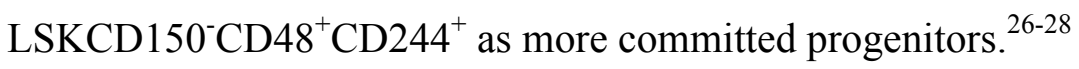

A hierarchy of hematopoietic cell differentiation continues to be established using both cell surface marker analysis and in vitro colony forming and functional assays. HSC, as multipotent progenitors, sit at the top of the hierarchy and possess high capacity for selfrenewal and differentiation. Downstream on the hierarchy, HSC lose their self-renewing ability and develop into MPP that give rise to several lineages of blood cells. ${ }^{25}$ MPP represent a heterogeneous population of stem/progenitor cells, and remain under investigation in terms of their subsets and their differentiative potential. ${ }^{26,29-31}$

In terms of differentiation to give a diversity of APC, the myeloid pathway is of particular interest. HSC give rise to common myeloid progenitors (CMP) and common lymphoid progenitors (CLP) through a multipotential progenitor (MPP). ${ }^{31,32} \mathrm{CMP}$ then differentiate to give granulocyte-macrophage progenitors (GMP) and megakaryocyte-erythroid progenitors (MEP). GMP are the progenitors of granulocytic and macrophage/monocytic cells including neutrophils, eosinophils, basophils, and monocytes. MEP give rise to red blood cells and megakaryocytes. CLP give rise to lymphoid and NK cell progenitors, followed by generation of mature T cells, B cells and NK cells. The Flt3 ${ }^{+}$subset of CMP and CLP give rise to dendritic cells (DC). ${ }^{33}$ Two further progenitors have recently been defined in relation to DC development (Figure 1). The earliest is the MDP, a myeloid dendritic progenitor which overlaps with the CMP and CLP, but not the GMP population. ${ }^{34,35}$ A downstream common dendritic progenitor (CDP) which responds to Flt3L has been identified as a specific progenitor of conventional (c)DC and plasmacytoid (p)DC. ${ }^{36,37}$ The relationship between CDP and the previously defined CLP, CMP and MDP populations is still under investigation. 


\section{HSC ARE DISTRIBUTED AND NOT RESTRICTED TO BONE MARROW}

Bone marrow primarily provides niches for HSC seeding and contributes the microenvironment which supports self-renewal and differentiation. In the adult, HSC migration from $\mathrm{BM}$ into the bloodstream in the steady-state is important for maintaining homeostasis. Collection of stem cells for transplantation in a clinical setting takes advantage of this natural migratory phenomenon by enforcing the release, or by 'mobilising' HSC, from bone marrow by infusion of chemotherapeutic drugs or cytokines like granulocyte-colony stimulating factor (G-CSF). HSC can then be collected from blood for stem cell transplantation. Adoptive transfer then leads to reconstitution of all hematopoietic cells after HSC home to and infiltrate bone marrow. One enigma is that HSC introduced into the peripheral blood circulation can traffic back into lymphatic circulation and into bone marrow, and so find their niches in this tissue (Figure 2) ${ }^{38}$ It is also clear that following intravenous infusion, HSC localize in spleen and other extramedullary tissue niches (Figure 2). ${ }^{38}$

Several mechanisms are known to regulate HSC homing into niches. CXCL12 or stromaderived factor-1 (SDF-1) and its receptor CXCR4 are master regulators of HSC migration through blood during embryonic development, consistent with reduction of myeloid progenitors in $\mathrm{CXCR} 4^{-/-}$and CXCL12 $2^{-/-}$mice. ${ }^{39,40} \mathrm{HSC}$ also use VLA-4 (integrin $\alpha 4 \beta 1$ ) to localise themselves in contact with blood vessels in bone marrow via binding to VCAM-1 expressed on bone marrow stromal or endothelial cells (Figure 2). ${ }^{41}$ Migration of HSC into extramedullary hematopoietic organs such as spleen and liver is also mediated via interaction of VLA-4 with VCAM-1, ahead of returning to the appropriate niche that secretes SDF-1 (CXCL12) (Figure 2). ${ }^{41}$

Studies now show that HSC can enter and circulate through the lymphatic system. The egress of HSC from bone marrow into extramedullary tissues depends on sphingosine-1phosphate receptor $\left(\mathrm{S}_{1} \mathrm{P}_{1}\right)$ (Figure 2 ). $\mathrm{HSC}$ also use $\mathrm{S}_{1} \mathrm{P}_{1}$, to migrate across lymphatic 
vessels and so restore specialized myeloid cells in peripheral tissues. ${ }^{42}$ HSC express toll-like receptors (TLR), and their co-receptors MD-2 and CD14, required for recognition of pathogen associated molecular patterns such as bacterial lipopolysaccharide (LPS). ${ }^{43}$ Interaction of TLR with LPS signals myeloid differentiation in migratory HSC localized in peripheral tissues. LPS was found to amplify the differentiation of HSC in local tissues, and to reduce the expression of $\mathrm{S}_{1} \mathrm{P}_{1}$ on HSC, so leading to retention of HSC within tissue sites. ${ }^{42}$

During inflammatory responses, the phagocytic activity of sinusdoidal-lining macrophages is dramatically increased in order to remove invading pathogens. During inflammation, HSC protect themselves from macrophage uptake by upregulating CD47, an immunoglobulin-like protein which interacts with integrins and thrombospondins to protect HSC from reactive phagocytosis. ${ }^{44-46}$ CD47 interacts with its receptor, SIRP $\alpha$ on macrophages and dendritic cells, to prevent phagocytosis, so ensuring survival of HSC during inflammation. ${ }^{44,45}$

\section{NICHES FOR HEMATOPOIESIS ARE DISTRIBUTED}

Several niches have been described as sites for HSC maintenance, including endosteum of bone and vascular niches in bone marrow and spleen. ${ }^{47,48}$ In adult mice, the majority of HSC reside within osteoblastic and vascular niches in bone marrow where most hematopoietic activity occurs, whilst smaller numbers reside in vascular niches in other tissues.

Bone marrow niches contain specialized cells that provide membrane-bound and secreted growth factors to support HSC growth. ${ }^{49,50}$ Many studies have focused on the role of endosteal cells lining the inner surface of bone at the interface with bone marrow, in HSC maintenance. ${ }^{14,51-54}$ Endosteal cells differentiate into osteoblasts which support cell-to-cell contact with HSC, mediated through multiple adhesive interactions including homotypic interactions involving N-cadherin (Figure 2). Osteopontin (OPN) induces HSC retention and 
quiescence in the bone marrow by binding to several integrins or to CD44, resulting in downregulation of Jagged1 expression on stromal cells and Notch1 expression on HSC. ${ }^{55}$ Endosteal cells produce growth factors like stem cell factor (SCF) which support HSC function and survival (Figure 2). Angiopoietin (Ang-1) and thrombopoietin (TPO) promote quiescence of HSC, while SDF-1 (CXCL12) regulates migration of HSC within the bone marrow. ${ }^{56-58}$ The endosteum also comprises the bone resorbing osteoclasts and a balance between osteoblastic and osteoclastic activities in the bone marrow is important for development of HSC. ${ }^{59}$

The highly vascularised nature of the endosteum is also consistent with endothelial cells having a critical role in regulation of HSC development in bone marrow. ${ }^{50}$ Vascular niches are considered alternate sites for HSC maintenance. During embyogenesis, HSC arise from progenitors located in perivascular sites, and HSC in extramedullary tissues like liver and spleen are located in sinusoidal or vascular areas in the absence of osteoblastic cells.

Lifelong maintenance of the HSC pool depends on protecting HSC from premature exhaustion under conditions of stress. Quiescence in terms of cell cycle is a common property of niche-associated HSC.-Although HSC divide infrequently, the entire HSC pool turns over every few weeks. In mice, dormant HSC divide every 145 days or 5 times per lifetime. ${ }^{28}$ These multilineage long-term self-renewing cells create a silent reservoir of HSC during homeostasis. Upon stimulation with G-CSF, dormant HSC enter cell cycle, and then switch back to dormancy. HSC can reversibly undergo self-renewal under conditions of stress. ${ }^{28}$ Quiescence is maintained by signaling within the niche, which induces the Tie-2 tyrosine kinase receptor on HSC which interacts with angiopoietin-1 (Ang-1) on osteoblasts $^{57}$, as well as the TPO/Mpl and $\mathrm{Wnt} / \beta$-catenin signaling interactions, also important for HSC quiescence (Figure 2). ${ }^{60}$ 
Vascular conduits are the major highways by which hematopoietic cells and hematopoietic progenitors traffic to liver and spleen in adults. ${ }^{61-63}$ It is generally accepted that a small number of hematopoietic progenitors circulate through peripheral sites and then home back to the bone marrow. ${ }^{64,65}$ Consistent with HSC migration, several studies have identified hematopoietic progenitors in heart. ${ }^{66-68}$ Indeed, c-kit ${ }^{+}$cells isolated in the heart after myocardial infarction have been reported to have a bone marrow origin ${ }^{69-71}$. Hematopoietic progenitors from bone marrow can give rise to microglia following transplantation into brain. $^{72,73}$ After brain injury it is possible that HSC or other hematopoietic progenitors from bone marrow may enter the brain and differentiate to become APC. There are also reports of the presence of hematopoietic progenitors in peripheral tissue sites like kidney ${ }^{74}$, $\operatorname{skin}^{75}$, and intestinal tract. ${ }^{76}$ Such progenitors can give rise to hematopoietic cells specific to each tissue site. Similarly, Langerhans cells in skin derive from self-renewing hematopoietic progenitors which colonise the epidermis during embryonic development. ${ }^{77}$

\section{HEMATOPOIESIS LEADING TO A DISTRIBUTED PATTERN OF MYELOID AND DENDRITIC CELLS IN MULTIPLE TISSUES}

Hematopoiesis leading to APC formation now appears to reflect a complex set of developmental pathways originating from progenitors in bone marrow, leading to a diverse range of cells in different states of development within tissue sites such as bone marrow, liver, spleen and other lymphoid and non-lymphoid organs. ${ }^{78} \mathrm{DC}$ emerge from bone marrow progenitors, but the exact progenitors that give rise to DC and how they relate to known progenitors of lymphoid and myeloid cells in vivo is still under investigation (Figure 1). Recent developmental studies show that DC subsets and monocytes/macrophages are generated along a myeloid pathway. ${ }^{34,79}$ Data from parabiotic mice also support the hypothesis that lymphoid tissue DC and monocytes share a common bone marrow-derived 
macrophage/dendritic progenitor (MDP), identified as a Lin'Scal'c$\mathrm{Kit}^{\mathrm{hi}} \mathrm{CD} 115^{+} \mathrm{CX} 3 \mathrm{CR} 1^{+} \mathrm{Flt} 3^{+}$subset also expressing CD34 and CD16/32. ${ }^{35,80}$ A more committed, distinct bone marrow progenitor called the common DC progenitor (CDP) has been identified as a $\mathrm{Lin}^{-} \mathrm{Sca}^{+}{ }^{+} \mathrm{c}-\mathrm{Kit}^{\mathrm{lo}} \mathrm{CD} 115^{+} \mathrm{Flt3} 3^{+}$subset which gives rise $\mathrm{cDC}$ and $\mathrm{pDC}$ (Figure 1). ${ }^{35,37}$ Data such as these supports the concept that development of monocytes and macrophages is separated from that of DC before these cell types migrate into peripheral lymphoid tissues.

Multiple DC subsets have now been identified in tissues around the body. Their immune capacity varies in terms of ability to take up antigen and presence of inflammatory stimuli. In thymus, DC derive from an intrathymic lymphoid progenitor and represent a specialized subset important in creating a self-tolerant $\mathrm{T}$ cell repertoire ${ }^{78}$. In murine spleen, several subsets are recognized including $\mathrm{cDC}$ and pDC (Figure 1), each phenotypically and functionally distinct. Conventional DC are small, non-granular cells comprising two subsets of $\mathrm{CD} 8 \alpha^{+}$and $\mathrm{CD} 8 \alpha^{-}$cDC. ${ }^{81}$ Counterpart cells can also be found in humans, free of infection and inflammation. ${ }^{82}$ The majority of DC in spleen are CD $8 \alpha^{-}$cDC with only $\sim 20 \%$ cDC of CD8 $\alpha^{+}$phenotype. ${ }^{83}$ The $\mathrm{CD} 8 \alpha^{+} \mathrm{cDC}$ are localised in the T-cell rich areas or periarteriolar lymphatic sheath (PALS) of spleen, while the CD8 $\alpha^{-} \mathrm{cDC}$ are found in the marginal zone. $\mathrm{CD} 8 \alpha^{-} \mathrm{cDC}$ can migrate into the T-cell zone upon activation with bacterial lipopolysaccharides (LPS). ${ }^{84,85}$ Plasmacytoid DC have strong capacity to secrete type-1 interferon (IFN- $\alpha$ ) upon viral or bacterial infection, and express CD11c, B220, CD36, CD4, CD68, and MHC-II on their cell surface. The function of $\mathrm{pDC}$ is linked to their expression of TLR-7 and TLR-9 which detect viral nucleic acid in early endosomes. ${ }^{86}$

Monocytes can also be induced to differentiate in vitro under the influence of inflammatory cytokines like GM-CSF and TNF- $\alpha$ to give monocyte-derived DC (mo-DC). These have been commonly studied as a model DC type and used in intervention or 
immunotherapy against malignancies. However, DC produced by this protocol represent inflammatory DC, and are distinct from steady-state cDC. It is not yet clear whether mo-DC correspond to any DC subsets in steady-state lymphoid organs. ${ }^{87}$ Other myeloid subsets described in spleen include TNF/iNOS-producing (Tip) $\mathrm{DC}^{88}$ and inflammatory monocytes. ${ }^{89}$

In general, DC exist in peripheral tissues in an immature state and possess high capability for capturing and processing antigens from the local environment. After endocytosis of foreign antigens, these immature DC in peripheral tissues migrate to lymphoid organs where they undergo antigen processing and cell maturation, whereby DC upregulate co-stimulatory molecules like CD40, CD69, CD80, and CD86. Mature DC possess high capacity for presentation of antigen to naïve $\mathrm{T}$ lymphocytes ${ }^{90,91}$, and have high capability for cross presentation of endocytosed antigen for subsequent $\mathrm{CD} 8^{+} \mathrm{T}$ cell activation. ${ }^{92}$ Presentation of antigenic peptides by DC expressing appropriate co-stimulatory molecules results in activation of $\mathrm{T}$ cells for immunogenic responses, while antigen presentation without costimulation leads to $\mathrm{T}$ cell activation for tolerogenic responses. ${ }^{93,94} \mathrm{~A}$ wide range of $\mathrm{DC}$ subsets are therefore formed which act as extremely important central controllers of tolerance and immunity.

\section{EXTRAMEDULLARY SITES FOR MYELOPOIESIS OF DC}

DC can also develop within peripheral tissue sites and this has clearly been demonstrated for Langerhans cells. Cells of host origin were found several months after bone marrow transplantation $^{77}$, indicating that skin Langerhans cells are derived from tissue-restricted myeloid progenitors. Thus, DC development from progenitors within peripheral tissue sites might be possible given the distribution of HSC within tissues, and the potential for hematopoietic niches in multiple tissue sites. However, the extent to which this happens is not yet fully understood. In particular, spleen appears to support extramedullary 
hematopoiesis for development of tissue-specific APC. In humans and mice, steady statespleen contains $\mathrm{CDC}$ and $\mathrm{pDC}$ which are maintained by the replenishment of pre-DC, or precursors of $\mathrm{cDC}$ and $\mathrm{pDC}$ which derive from progenitors in bone marrow. We now present evidence that distinct dendritic-like cells appear to arise in spleen from endogenous selfrenewing progenitors (Figure 1). ${ }^{95}$

In vitro studies from this lab showed that continuous long-term stromal cultures (LTC) of spleen support production of distinct dendritic-like cells which are large cells expressing CD11c, CD11b, and MHC-I, but not MHC-II. ${ }^{96}$ Since these cells resembled immature myeloid DC, they were named LTC-DC..$^{96-100}$ The phenotype of cells produced has remained stable over years of culture with characteristic expression of CD11c, CD11b, CD80, CD86, MHC-I, CD205 but not MHC-II CD8 $\alpha$ or B220. ${ }^{96,100}$ Gene expression studies have shown that LTC-DC express genes encoding several cell surface molecules expressed by DC. ${ }^{101,102}$ LTC are distinct from other in vitro cultures for DC production in that stromal cells support DC production without addition of exogenous inflammatory cytokines, reflecting the capacity of the spleen stromal cells to support DC haematopoiesis. ${ }^{103}$ The continual production of immature myeloid DC in LTC led to the hypothesis that hematopoietic stem or progenitor cells are maintained within LTC. ${ }^{104,105}$ Ongoing investigations have now supported that hypothesis.

Recently it was shown that LTC-DC have an in vivo counterpart cell, distinguishable from other DC subtypes on the basis of marker expression. ${ }^{106}$ These cells are distinct from cDC by their higher endocytic activity, absence of MHC-II expression, and their RelBindependent development. ${ }^{107,108}$ They are also phenotypically and functionally distinct from monocytes. ${ }^{106}$ The in vivo counterpart of LTC-DC, termed 'L-DC' has now been identified in both adult and neonatal spleen, and these cells possess highly endocytic activity, and can cross-present antigens to $\mathrm{CD} 8^{+} \mathrm{T}$ cells, with very limited ability to stimulate $\mathrm{CD} 4^{+} \mathrm{T}$ cell 
responses. ${ }^{106}$ The inability of L-DC to induce a helper T cell response is likely due to the absence or low MHC-II expression on these cells. ${ }^{100}$ LTC-DC and L-DC are readily distinguished from monocytes which cannot cross-present antigen to $\mathrm{CD}^{+} \mathrm{T}$ cells. ${ }^{105,106}$

Hematopoietic progenitors in LTC and their counterparts in vivo have been investigated in order to substantiate the development of L-DC as a distinct APC in the context of the spleen microenvironment. Based on the finding that a population of small cells is maintained in $\mathrm{LTC}$, which reflect $\mathrm{Lin}^{-} \mathrm{c}-\mathrm{kit}^{+} \mathrm{Sca}-1^{+}$progenitors $^{109}$, the question was raised as to whether HSC or MPP could serve the role as L-DC progenitors in spleen. ${ }^{95}$ HSC derived from spleen ${ }^{104}$ and bone marrow ${ }^{105}$ have now been shown to act as progenitors of L-DC in LTC. When these same subsets of HSC from spleen or bone marrow were adoptively transferred into lethally irradiated mice there was a bias favouring production of L-DC over other DC subsets in spleen. ${ }^{104,105}$ These data raise the possibility that APC can develop in spleen from endogenous self-renewing HSC and have tissue-specific function perhaps related to bloodborne antigens. Further studies are underway to gain complete understanding of the development of this putative novel DC subset in the splenic context.

\section{CONCLUSION}

Indeed, there is much to be learned about tissue niches for HSC and about tissue-specific hematopoiesis for production of APC, before their importance in tissue-specific inflammation and immunity can be interpreted and considered in terms of immunotherapy. Indeed, a role for self-renewing tissue-specific progenitors in production of tissue-specific APC during the steady-state and during inflammation can be justified in terms of tissue-specific immunity reflecting some level of diversification and compartmentalisation of the immune response. 


\section{ACKNOWLEDGEMENTS}

This work was supported by project grant 585443 from the National Health and Medical Research Council of Australia to HO. SP was supported by a postgraduate scholarship from the Royal Thai Government.

1. Baron MH. Embryonic origins of mammalian hematopoiesis. Exp Hematol 2003; 31(12): 1160-9.

2. McGrath KE, Palis J. Hematopoiesis in the yolk sac: more than meets the eye. Exp Hematol 2005; 33(9): 1021-8.

3. Galloway JL, Zon LI. Ontogeny of hematopoiesis: examining the emergence of hematopoietic cells in the vertebrate embryo. Curr Top Dev Biol 2003; 53: 139-58.

4. Kingsley PD, Malik J, Fantauzzo KA, Palis J. Yolk sac-derived primitive erythroblasts enucleate during mammalian embryogenesis. Blood 2004; 104(1): 1925.

5. Palis J, Robertson S, Kennedy M, Wall C, Keller G. Development of erythroid and myeloid progenitors in the yolk sac and embryo proper of the mouse. Development 1999; 126(22): 5073-84.

6. Gekas C, Dieterlen-Lievre F, Orkin SH, Mikkola HK. The placenta is a niche for hematopoietic stem cells. Dev Cell 2005; 8(3): 365-75.

7. Ema H, Nakauchi H. Expansion of hematopoietic stem cells in the developing liver of a mouse embryo. Blood 2000; 95(7): 2284-8.

8. Ogawa M. Changing phenotypes of hematopoietic stem cells. Exp Hematol 2002; 30: 3-6.

9. Olsen BR, Reginato AM, Wang W. Bone development. Annu Rev Cell Dev Biol 2000; 16: $191-220$.

10. Mikkola HK, Orkin SH. The journey of developing hematopoietic stem cells. Development 2006; 133(19): 3733-44.

11. Godin I, Garcia-Porrero JA, Dieterlen-Lievre F, Cumano A. Stem cell emergence and hemopoietic activity are incompatible in mouse intraembryonic sites. $J$ Exp Med 1999; 190(1): 43-52. 
12. Bertrand JY, Desanti GE, Lo-Man R, Leclerc C, Cumano A, Golub R. Fetal spleen stroma drives macrophage commitment. Development 2006; 133(18): 3619-28.

13. Weissman IL. Stem cells: units of development, units of regeneration, and units in evolution. Cell 2000; 100(1): 157-68.

14. Wilson A, Trumpp A. Bone-marrow haematopoietic-stem-cell niches. Nat Rev Immunol 2006; 6(2): 93-106.

15. Zon LI. Intrinsic and extrinsic control of haematopoietic stem-cell self-renewal. Nature 2008; 453(7193): 306-13.

16. Karanu FN, Murdoch B, Gallacher L, Wu DM, Koremoto M, Sakano S et al. The notch ligand jagged-1 represents a novel growth factor of human hematopoietic stem cells. J Exp Med 2000; 192(9): 1365-72.

17. Thorsteinsdottir U, Sauvageau G, Humphries RK. Enhanced in vivo regenerative potential of HOXB4-transduced hematopoietic stem cells with regulation of their pool size. Blood 1999; 94(8): 2605-12.

18. Thorsteinsdottir U, Mamo A, Kroon E, Jerome L, Bijl J, Lawrence HJ et al. Overexpression of the myeloid leukemia-associated Hoxa9 gene in bone marrow cells induces stem cell expansion. Blood 2002; 99(1): 121-9.

19. Bhardwaj G, Murdoch B, Wu D, Baker DP, Williams KP, Chadwick K et al. Sonic hedgehog induces the proliferation of primitive human hematopoietic cells via BMP regulation. Nat Immunol 2001; 2(2): 172-80.

20. Reya T, Duncan AW, Ailles L, Domen J, Scherer DC, Willert K et al. A role for Wnt signalling in self-renewal of haematopoietic stem cells. Nature 2003; 423(6938): 40914.

21. Weissman IL, Anderson DJ, Gage F. Stem and progenitor cells: origins, phenotypes, lineage commitments, and transdifferentiations. Annu Rev Cell Dev Biol 2001; 17: 387-403.

22. Spangrude GJ, Heimfeld S, Weissman IL. Purification and characterization of mouse hematopoietic stem cells. Science 1988; 241(4861): 58-62.

23. Shizuru JA, Negrin RS, Weissman IL. Hematopoietic stem and progenitor cells: clinical and preclinical regeneration of the hematolymphoid system. Annu Rev Med 2005; 56: 509-38.

24. Bryder D, Rossi DJ, Weissman IL. Hematopoietic stem cells: the paradigmatic tissuespecific stem cell. Am J Pathol 2006; 169(2): 338-46.

25. Christensen JL, Weissman IL. Flk-2 is a marker in hematopoietic stem cell differentiation: a simple method to isolate long-term stem cells. Proc Natl Acad Sci U $S$ A 2001; 98(25): 14541-6. 
26. Kiel MJ, Yilmaz OH, Iwashita T, Terhorst C, Morrison SJ. SLAM family receptors distinguish hematopoietic stem and progenitor cells and reveal endothelial niches for stem cells. Cell 2005; 121(7): 1109-21.

27. Papathanasiou P, Attema JL, Karsunky H, Xu J, Smale ST, Weissman IL. Evaluation of the Long-Term Reconstituting Subset of Hematopoietic Stem Cells with CD150. Stem Cells 2009.

28. Wilson A, Laurenti E, Oser G, van der Wath RC, Blanco-Bose W, Jaworski M et al. Hematopoietic stem cells reversibly switch from dormancy to self-renewal during homeostasis and repair. Cell 2008; 135(6): 1118-29.

29. Adolfsson J, Mansson R, Buza-Vidas N, Hultquist A, Liuba K, Jensen CT et al. Identification of Flt3+ lympho-myeloid stem cells lacking erythro-megakaryocytic potential a revised road map for adult blood lineage commitment. Cell 2005; 121(2): 295-306.

30. Arinobu Y, Mizuno S, Chong Y, Shigematsu H, Iino T, Iwasaki H et al. Reciprocal activation of GATA-1 and PU.1 marks initial specification of hematopoietic stem cells into myeloerythroid and myelolymphoid lineages. Cell Stem Cell 2007; 1(4): 416-27.

31. Kondo M, Weissman IL, Akashi K. Identification of clonogenic common lymphoid progenitors in mouse bone marrow. Cell 1997; 91(5): 661-72.

32. Akashi K, Traver D, Miyamoto T, Weissman IL. A clonogenic common myeloid progenitor that gives rise to all myeloid lineages. Nature 2000; 404(6774): 193-7.

33. Karsunky H, Merad M, Cozzio A, Weissman IL, Manz MG. Flt3 ligand regulates dendritic cell development from Flt3+ lymphoid and myeloid-committed progenitors to Flt3+ dendritic cells in vivo. $J$ Exp Med 2003; 198(2): 305-13.

34. Fogg DK, Sibon C, Miled C, Jung S, Aucouturier P, Littman DR et al. A clonogenic bone marrow progenitor specific for macrophages and dendritic cells. Science 2006; 311(5757): 83-7.

35. Liu K, Victora GD, Schwickert TA, Guermonprez P, Meredith MM, Yao K et al. In vivo analysis of dendritic cell development and homeostasis. Science 2009; 324(5925): 392-7.

36. Naik SH. Demystifying the development of dendritic cell subtypes, a little. Immunol Cell Biol 2008; 86(5): 439-52.

37. Onai N, Obata-Onai A, Schmid MA, Ohteki T, Jarrossay D, Manz MG. Identification of clonogenic common Flt3+M-CSFR+ plasmacytoid and conventional dendritic cell progenitors in mouse bone marrow. Nat Immunol 2007; 8(11): 1207-16.

38. Morita Y, Iseki A, Okamura S, Suzuki S, Nakauchi H, Ema H. Functional characterization of hematopoietic stem cells in the spleen. Exp Hematol 2011; 39(3): 351-359 e3. 
39. Ma Q, Jones D, Borghesani PR, Segal RA, Nagasawa T, Kishimoto T et al. Impaired B-lymphopoiesis, myelopoiesis, and derailed cerebellar neuron migration in CXCR4and SDF-1-deficient mice. Proc Natl Acad Sci U S A 1998; 95(16): 9448-53.

40. Nagasawa T, Hirota S, Tachibana K, Takakura N, Nishikawa S, Kitamura Y et al. Defects of B-cell lymphopoiesis and bone-marrow myelopoiesis in mice lacking the CXC chemokine PBSF/SDF-1. Nature 1996; 382(6592): 635-8.

41. Wright DE, Bowman EP, Wagers AJ, Butcher EC, Weissman IL. Hematopoietic stem cells are uniquely selective in their migratory response to chemokines. $J$ Exp Med 2002; 195(9): 1145-54.

42. Massberg S, von Andrian UH. Novel trafficking routes for hematopoietic stem and progenitor cells. Ann N Y Acad Sci 2009; 1176: 87-93.

43. Nagai Y, Garrett KP, Ohta S, Bahrun U, Kouro T, Akira S et al. Toll-like receptors on hematopoietic progenitor cells stimulate innate immune system replenishment. Immunity 2006; 24(6): 801-12.

44. Brown EJ, Frazier WA. Integrin-associated protein (CD47) and its ligands. Trends Cell Biol 2001; 11(3): 130-5.

45. Blazar BR, Lindberg FP, Ingulli E, Panoskaltsis-Mortari A, Oldenborg PA, lizuka K et al. CD47 (integrin-associated protein) engagement of dendritic cell and macrophage counterreceptors is required to prevent the clearance of donor lymphohematopoietic cells. J Exp Med 2001; 194(4): 541-9.

46. Jaiswal S, Jamieson CH, Pang WW, Park CY, Chao MP, Majeti R et al. CD47 is upregulated on circulating hematopoietic stem cells and leukemia cells to avoid phagocytosis. Cell 2009; 138(2): 271-85.

47. Adams GB, Scadden DT. The hematopoietic stem cell in its place. Nat Immunol 2006; 7(4): 333-7.

48. Suda T, Arai F, Hirao A. Hematopoietic stem cells and their niche. Trends Immunol 2005; 26(8): 426-33.

49. Li L, Xie T. Stem cell niche: structure and function. Annu Rev Cell Dev Biol 2005; 21: 605-31.

50. Kiel MJ, Morrison SJ. Uncertainty in the niches that maintain haematopoietic stem cells. Nat Rev Immunol 2008; 8(4): 290-301.

51. Chan CK, Chen CC, Luppen CA, Kim JB, DeBoer AT, Wei K et al. Endochondral ossification is required for haematopoietic stem-cell niche formation. Nature 2009; 457(7228): 490-4.

52. Moore KA, Lemischka IR. Stem cells and their niches. Science 2006; 311(5769): 1880-5. 
53. Calvi LM, Adams GB, Weibrecht KW, Weber JM, Olson DP, Knight MC et al. Osteoblastic cells regulate the haematopoietic stem cell niche. Nature 2003; 425(6960): 841-6.

54. Zhang J, Niu C, Ye L, Huang H, He X, Tong WG et al. Identification of the haematopoietic stem cell niche and control of the niche size. Nature 2003; 425(6960): 836-41.

55. Nilsson SK, Johnston HM, Whitty GA, Williams B, Webb RJ, Denhardt DT et al. Osteopontin, a key component of the hematopoietic stem cell niche and regulator of primitive hematopoietic progenitor cells. Blood 2005; 106(4): 1232-9.

56. Petit I, Szyper-Kravitz M, Nagler A, Lahav M, Peled A, Habler L et al. G-CSF induces stem cell mobilization by decreasing bone marrow SDF-1 and up-regulating CXCR4. Nat Immunol 2002; 3(7): 687-94.

57. Arai F, Hirao A, Ohmura M, Sato H, Matsuoka S, Takubo K et al. Tie2/angiopoietin1 signaling regulates hematopoietic stem cell quiescence in the bone marrow niche. Cell 2004; 118(2): 149-61.

58. Yoshihara H, Arai F, Hosokawa K, Hagiwara T, Takubo K, Nakamura Y et al. Thrombopoietin/MPL signaling regulates hematopoietic stem cell quiescence and interaction with the osteoblastic niche. Cell Stem Cell 2007; 1(6): 685-97.

59. Seeman E, Delmas PD. Bone quality--the material and structural basis of bone strength and fragility. $N$ Engl J Med 2006; 354(21): 2250-61.

60. Arai F, Yoshihara H, Hosokawa K, Nakamura Y, Gomei Y, Iwasaki H et al. Niche regulation of hematopoietic stem cells in the endosteum. Ann N Y Acad Sci 2009; 1176: $36-46$.

61. Taniguchi H, Toyoshima T, Fukao K, Nakauchi H. Presence of hematopoietic stem cells in the adult liver. Nat Med 1996; 2(2): 198-203.

62. Taniguchi H, Toyoshima T, Fukao K, Nakauchi H. Evidence for the presence of hematopoietic stem cells in the adult liver. Transplant Proc 1995; 27(1): 196-9.

63. Morrison SJ, Uchida N, Weissman IL. The biology of hematopoietic stem cells. Annu Rev Cell Dev Biol 1995; 11: 35-71.

64. Wright DE, Wagers AJ, Gulati AP, Johnson FL, Weissman IL. Physiological migration of hematopoietic stem and progenitor cells. Science 2001; 294(5548): 1933-6.

65. Bhattacharya D CA, Ooi AG, Rossi DJ, Bryder D, Weissman IL. Niche recycling through division-independent egress of hematopoietic stem cells. J Exp Med 2009; 23(206): 2837-2850. 
66. Anversa P, Nadal-Ginard B. Myocyte renewal and ventricular remodelling. Nature 2002; 415(6868): 240-3.

67. Asakura A, Rudnicki MA. Side population cells from diverse adult tissues are capable of in vitro hematopoietic differentiation. Exp Hematol 2002; 30(11): 1339-45.

68. Hierlihy AM, Seale P, Lobe CG, Rudnicki MA, Megeney LA. The post-natal heart contains a myocardial stem cell population. FEBS Lett 2002; 530(1-3): 239-43.

69. Altarche-Xifró W CC, Kaschina E, Grzesiak A, Slavic S, Dong J, Kappert K, Steckelings M, Imboden H, Unger T, Li J. Cardiac c-kit+AT2+ Cell Population is Increased in Response to Ischemic Injury and Supports Cardiomyocyte Performance. stem cells 2009; 27: 2488-2497.

70. Fazel S CM, Chen L, Li S, Angoulvant D, Fedak P, Verma S, Weisel RD, Keating A, Li RK. Cardioprotective c-kit+ cells are from the bone marrow and regulate the myocardial balance of angiogenic cytokines. J Clin Invest 2006; 116(7): 1865-1877.

71. Kajstura J RM, Whang B, Cascapera S, Hosoda T, Bearzi C, Nurzynska D, Kasahara H, Zias E, Bonafé M, Nadal-Ginard B, Torella D, Nascimbene A, Quaini F, Urbanek $\mathrm{K}$, Leri A, Anversa P. Bone marrow cells differentiate in cardiac cell lineages after infarction independently of cell fusion. Circ Res 2005; 96: 127-137.

72. Hess DC AT, Hill WD, Studdard AM, Carothers J, Masuya M, Fleming PA, Drake CJ, Ogawa M.:Hematopoietic origin of microglial and perivascular cells in brain. Exp Neurol 2004; 186: 134-144.

73. Massengale M, Wagers AJ, Vogel H, Weissman IL. Hematopoietic cells maintain hematopoietic fates upon entering the brain. $J$ Exp Med 2005; 201(10): 1579-89.

74. Stroo I SG, Teske GJ, Florquin S, Leemans JC. Haematopoietic stem cell migration to the ischemic damaged kidney is not altered by manipulating the SDF-1/CXCR4-axis. Nephrol Dial Transplant 2009; 24(7): 2082-2088.

75. Merad M, Ginhoux F, Collin M. Origin, homeostasis and function of Langerhans cells and other langerin-expressing dendritic cells. Nat Rev Immunol 2008; 8(12): 935-47.

76. Chinen H MK, Sato T, Kamada N, Okamoto S, Hisamatsu T, Kobayashi T, Hasegawa H, Sugita A, Kinjo F, Fujita J, Hibi T. Lamina propria c-kit+ immune precursors reside in human adult intestine and differentiate into natural killer cells. Gastroenterology 2007; 133(2): 559-573.

77. Merad M, Manz MG, Karsunky H, Wagers A, Peters W, Charo I et al. Langerhans cells renew in the skin throughout life under steady-state conditions. Nat Immunol 2002; 3(12): 1135-41.

78. Shortman K, Liu YJ. Mouse and human dendritic cell subtypes. Nat Rev Immunol 2002; 2(3): 151-61. 
79. Auffray C, Emre Y, Geissmann F. Homeostasis of dendritic cell pool in lymphoid organs. Nat Immunol 2008; 9(6): 584-6.

80. Varol C, Landsman L, Fogg DK, Greenshtein L, Gildor B, Margalit R et al. Monocytes give rise to mucosal, but not splenic, conventional dendritic cells. $J$ Exp Med 2007; 204(1): 171-80.

81. Xu Y, Zhan Y, Lew AM, Naik SH, Kershaw MH. Differential development of murine dendritic cells by GM-CSF versus Flt3 ligand has implications for inflammation and trafficking. J Immunol 2007; 179(11): 7577-84.

82. McIlroy D TC, Grassi F, Samri A, Barrou B, Autran B, Debré P, Feuillard J, Hosmalin A. Investigation of human spleen dendritic cell phenotype and distribution reveals evidence of in vivo activation in a subset of organ donors. Blood 2001; 97(11): 3470-3477.

83. Vremec D, Pooley J, Hochrein H, Wu L, Shortman K. CD4 and CD8 expression by dendritic cell subtypes in mouse thymus and spleen. J Immunol 2000; 164(6): 297886.

84. Reis e Sousa C HS, Scharton-Kersten T, Jankovic D, Charest H, Germain RN, Sher A. In vivo microbial stimulation induces rapid CD40 ligand-independent production of interleukin 12 by dendritic cells and their redistribution to T cell areas. $J$ Exp Med 1997; 186(11): 1819-1829.

85. De Smedt T PB, Muraille E, Lespagnard L, Heinen E, De Baetselier P, Urbain J, Leo $\mathrm{O}$, Moser M. Regulation of dendritic cell numbers and maturation by lipopolysaccharide in vivo. J Exp Med 1996; 184(4): 1413-1424.

86. Gilliet M, Cao W, Liu YJ. Plasmacytoid dendritic cells: sensing nucleic acids in viral infection and autoimmune diseases. Nat Rev Immunol 2008; 8(8): 594-606.

87. Villadangos JA SP. Intrinsic and cooperative antigen-presenting functions of dendritic-cell subsets in vivo. Nat Rev Immunol 2007; 7(7): 543-555.

88. Serbina NV, Salazar-Mather TP, Biron CA, Kuziel WA, Pamer EG. TNF/iNOSproducing dendritic cells mediate innate immune defense against bacterial infection. Immunity 2003; 19(1): 59-70.

89. Sunderkötter C NT, Dillon MJ, Van Rooijen N, Stehling M, Drevets DA, Leenen PJ. Subpopulations of mouse blood monocytes differ in maturation stage and inflammatory response. $j$ immunol 2004; 172(7): 4410-4417.

90. Steinman RM. The dendritic cell system and its role in immunogenicity. Annu Rev Immunol 1991; 9: 271-96.

91. Steinman RM. Lasker Basic Medical Research Award. Dendritic cells: versatile controllers of the immune system. Nat Med 2007; 13(10): 1155-9. 
92. Heath WR, Belz GT, Behrens GM, Smith CM, Forehan SP, Parish IA et al. Crosspresentation, dendritic cell subsets, and the generation of immunity to cellular antigens. Immunol Rev 2004; 199: 9-26.

93. Steinman RM, Hawiger D, Liu K, Bonifaz L, Bonnyay D, Mahnke K et al. Dendritic cell function in vivo during the steady state: a role in peripheral tolerance. Ann NY Acad Sci 2003; 987: 15-25.

94. Steinman RM, Hawiger D, Nussenzweig MC. Tolerogenic dendritic cells. Annu Rev Immunol 2003; 21: 685-711.

95. Tan JK, Periasamy P, O'Neill HC. Delineation of precursors in murine spleen that develop in contact with splenic endothelium to give novel dendritic-like cells. Blood 2010; 115(18): 3678-85.

96. O'Neill HC, Wilson HL, Quah B, Abbey JL, Despars G, Ni K. Dendritic cell development in long-term spleen stromal cultures. Stem Cells 2004; 22(4): 475-86.

97. Ni K, O'Neill HC. The role of dendritic cells in T cell activation. Immunol Cell Biol 1997; 75(3): 223-30.

98. Ni K, O'Neill HC. Long-term stromal cultures produce dendritic-like cells. $\mathrm{Br} J$ Haematol 1997; 97(4): 710-25.

99. Ni K, O'Neill HC. Hemopoiesis in long-term stroma-dependent cultures from lymphoid tissue: production of cells with myeloid/dendritic characteristics. In Vitro Cell Dev Biol Anim 1998; 34(4): 298-307.

100. Quah B, Ni K, O'Neill HC. In vitro hematopoiesis produces a distinct class of immature dendritic cells from spleen progenitors with limited $\mathrm{T}$ cell stimulation capacity. Int Immunol 2004; 16(4): 567-77.

101. Wilson HL, O'Neill HC. Identification of differentially expressed genes representing dendritic cell precursors and their progeny. Blood 2003; 102(5): 1661-9.

102. Wilson HL, O'Neill HC. Dynamics of dendritic cell development from precursors maintained in stroma-dependent long-term cultures. Immunol Cell Biol 2003; 81(2): 144-51.

103. Ni K, O'Neill HC. Development of dendritic cells from GM-CSF-/- mice in vitro : GM-CSF enhances production and survival of cells. Dev Immunol 2001; 8(2): 133-46.

104. Tan JK, O'Neill HC. Hematopoietic stem cells in spleen have distinct differentiative potential for antigen presenting cells. J Cell Mol Med 2009.

105. Periasamy P, Tan JK, Griffiths KL, O'Neill HC. Splenic stromal niches support hematopoiesis of dendritic-like cells from precursors in bone marrow and spleen. Exp Hematol 2009; 37(9): 1060-71. 
106. Tan JK, Quah BJ, Griffiths KL, Periasamy P, Hey YY, O'Neill HC. Identification of a novel antigen cross-presenting cell type in spleen. J Cell Mol Med 2010.

107. Tan JK, Ni K, Le F, O'Neill HC. Hematopoiesis of immature myeloid dendritic cells in stroma-dependent spleen long-term cultures occurs independently of NF-KB/RelB function. Exp Hematol 2007; 35(10): 1580-93.

108. Wilson HL, Ni K, O'Neill HC. Proliferation of dendritic cell progenitors in long term culture is not dependent on granulocyte macrophage-colony stimulating factor. Exp Hematol 2000; 28(2): 193-202.

109. Wilson HL, Ni K, O'Neill HC. Identification of progenitor cells in long-term spleen stromal cultures that produce immature dendritic cells. Proc Natl Acad Sci U S A 2000; 97(9): 4784-9. 


\section{Figure Legends}

Figure 1 Myelopoiesis leading to dendritic cell development. The bone marrow maintains hematopoietic stem cells (HSC). Myeloid cells are produced from a downstream common myeloid progenitor (CMP). These further differentiate to give macrophage/dendritic progenitors (MDP) which are precursors of monocytes, macrophages and dendritic cells. Recently a common dendritic progenitor (CDP) was shown to give restricted development of splenic DC via a precursor detectable in both blood and spleen. A novel antigen presenting cell type has been characterized in murine spleen. These dendritic-like cells have been named 'L-DC' and appear to derive by direct differentiation from HSC in bone marrow and spleen.

Figure 2 The bone marrow microenvironment provides signals which control HSC selfrenewal, migration, and quiescence. (A) HSC migrate within the niche by interaction of SDF-1 (CXCL12) produced by osteoblasts (OB) with CXCR4 on HSC. HSC are maintained on the endosteal surface of bone through cell-cell interactions, including homotypic interactions involving $\mathrm{N}$-cadherin, and osteopontin (OPN) interaction with CD44 or integrins. Osteopontin supports retention of HSC in the niche by down regulation of Jagged-1 expression which interacts with Notch-1 on HSC. These interactions allow Tie-2 on HSC to interact with angiopoietin (Ang-1), and cKit to interact with stem cell factor (SCF) on the surface of osteoblasts. Angiopoietin (Ang1) and thrombopoietin (TPO) interactions with their receptors on HSC supports HSC quiescence. (B) HSC migrate from blood into extramedullary tissues via a sphingosine-1-phosphate (S1P) gradient. The interaction of S1P with its receptor $\left(\mathrm{S}_{1} \mathrm{P}_{1}\right)$, in combination with other molecules such as CXCR4 and VLA-4 which interact with ligands on endothelial cells (EC) (CXCL12 and VCAM-1), facilitates HSC migration into extramedullary tissues. The S1P level in tissues is lower due to 
S1P lyase activity. This results in localization of HSC within tissue niches for differentiation. HSC can also enter lymphatic tissues including bone marrow through the guidance of S1P. 


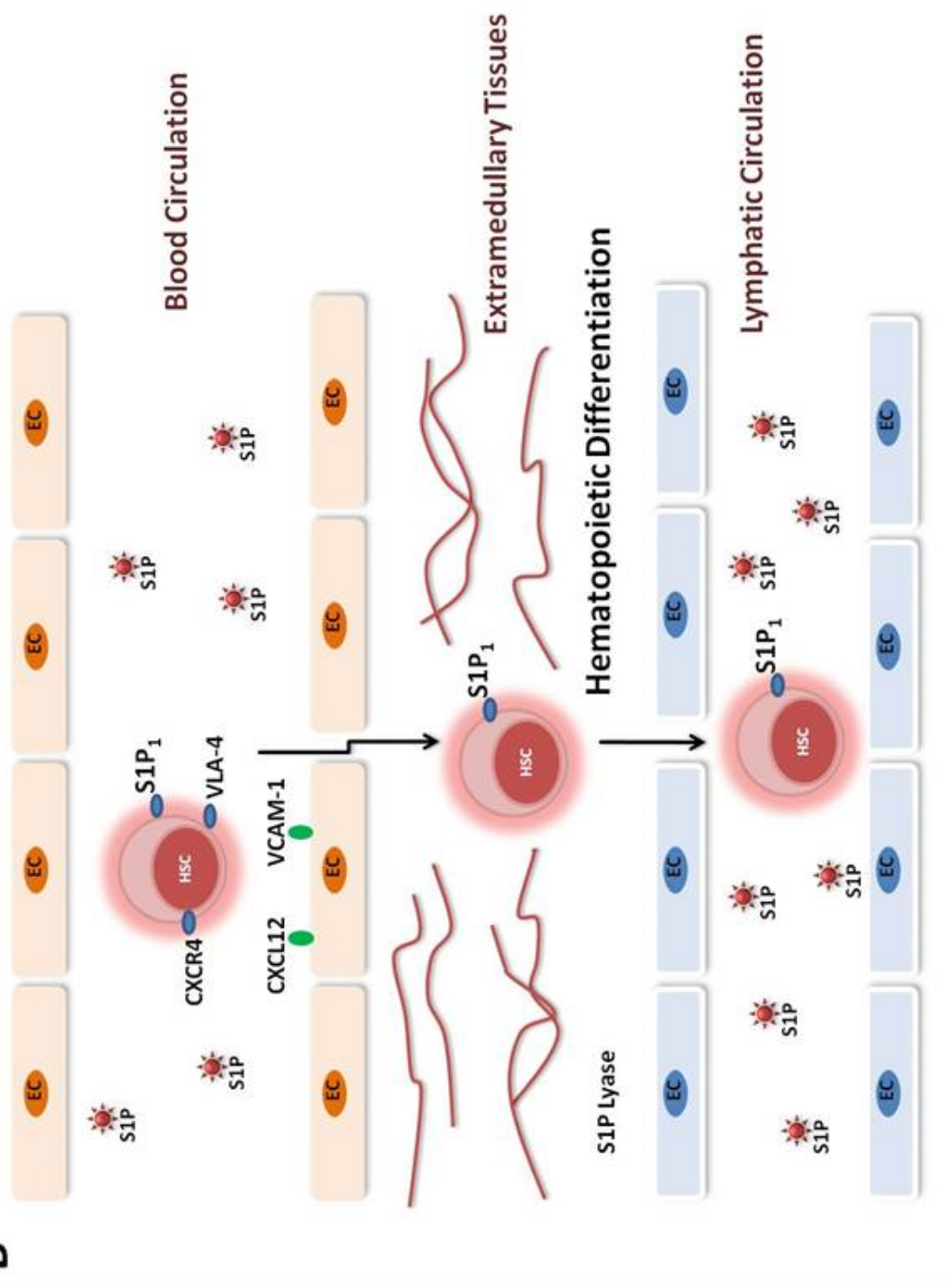

요

(๕)

(8)

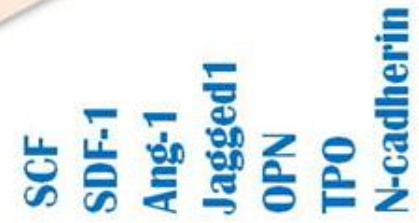

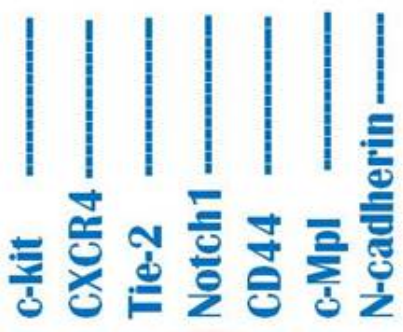




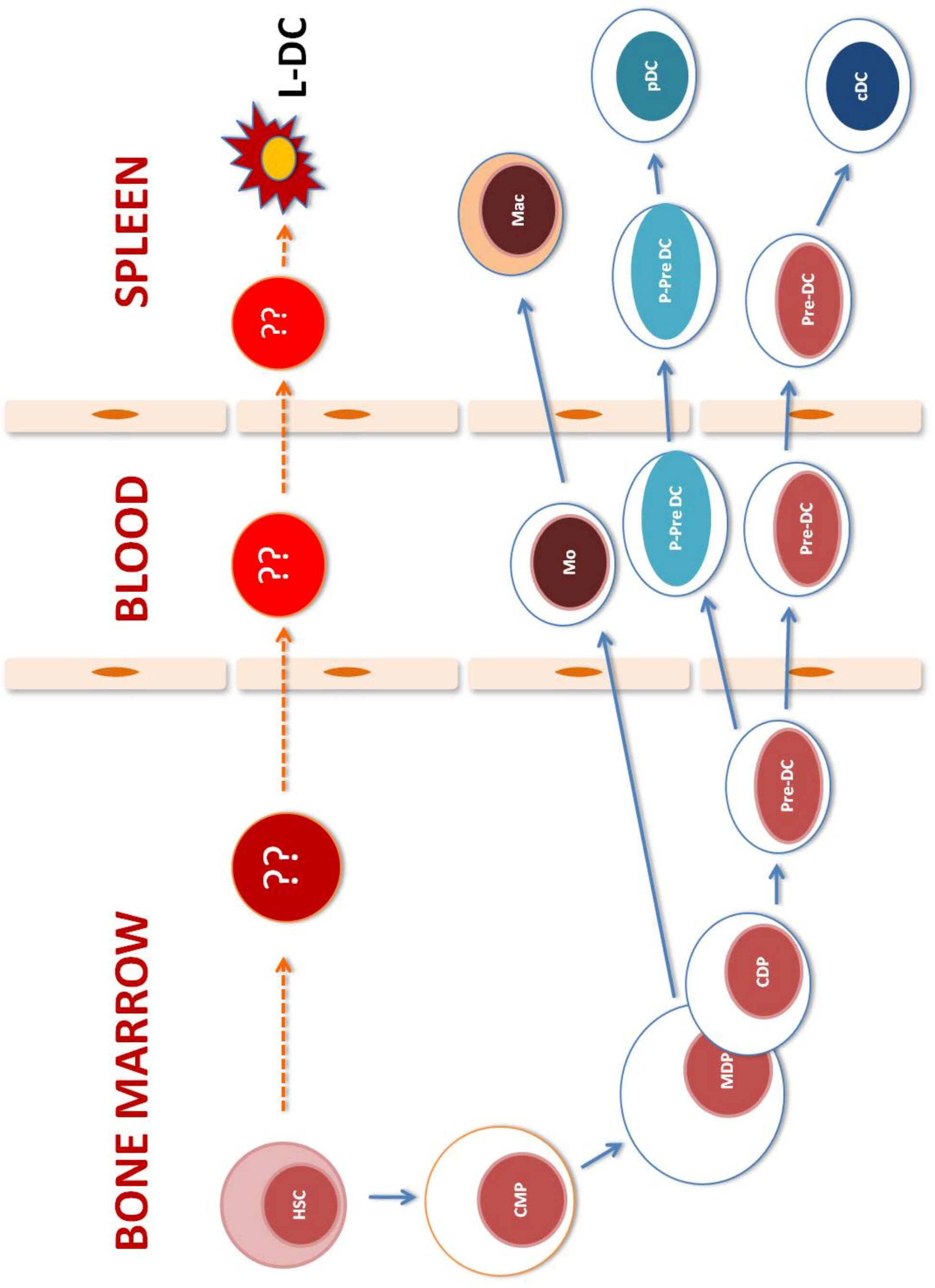

